\title{
The Role of MicroRNAs in Skin Fibrosis
}

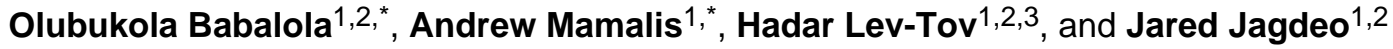 \\ ${ }^{1}$ Department of Dermatology, University of California at Davis, 3301 C Street, Sacramento, CA \\ 95816, USA \\ ${ }^{2}$ Dermatology Service, Sacramento VA Medical Center, Mather, CA 95655, USA \\ ${ }^{3}$ Department of Dermatology, Albert Einstein School of Medicine, Bronx, NY 10461
}

\begin{abstract}
Fibrotic skin disorders may be debilitating and impair quality of life. There are few effective treatment options for cutaneous fibrotic diseases. In this review, we discuss our current understanding of the role of microRNAs (miRNAs) in skin fibrosis. MiRNAs are a class of small, noncoding RNAs involved in skin fibrosis. These small RNAs range from 18 to 25 nucleotides in length and modify gene expression by binding to target messenger RNA (mRNA), causing degradation of the target mRNA or inhibiting the translation into proteins. We present an overview of the biogenesis, maturation and function of miRNAs. We highlight miRNA's role in key skin fibrotic processes including: transforming growth factor (TGF)-beta signaling, extracellular matrix (ECM) deposition, and fibroblast proliferation and differentiation. Some miRNAs are profibrotic and their upregulation favors these processes contributing to fibrosis, while antifibrotic miRNAs inhibit these processes and may be reduced in fibrosis. Finally we describe the diagnostic and therapeutic significance of miRNAs in the management of skin fibrosis. The discovery that miRNAs are detectable in serum, plasma, and other bodily fluids, and are relatively stable, suggests miRNAs may serve as valuable biomarkers to monitor disease progression and response to treatment. In the treatment of skin fibrosis, antifibrotic miRNAs may be upregulated using mimics and viral vectors. Conversely, profibrotic miRNAs may be downregulated by employing anti-miRNAs, sponges, erasers and masks. We believe that miRNA-based therapies hold promise as important treatments and may transform the management of fibrotic skin diseases by physicians.
\end{abstract}

\section{Keywords}

skin fibrosis; microRNA; miRNA; collagen; therapeutics

\section{Introduction}

Skin fibrosis is characterized by fibroblast proliferation and excessive synthesis as well as deposition of extracellular matrix (ECM) proteins, such as collagen, elastin, and fibrillin $[16,26]$. Skin fibrosis is a hallmark feature of several conditions, including scleroderma, keloids, hypertrophic scars and graft versus host disease [70]. Some of these fibrotic skin diseases have profound impact on duration and quality of life $[1,9,14,64,65]$. For instance, scleroderma affects approximately 100,000 people in the United States with a median survival rate of 11 years [70]. Fibrotic skin disorders are debilitating and are associated with low self-esteem, job discrimination, prejudicial societal reactions, isolation, depression and

Corresponding author: Jared Jagdeo, MD, MS, jrjagdeo@ gmail.com, Telephone: (917) 837-9796, Fax: (916) 451-7245.

These authors contributed equally to the preparation of this manuscript. 
other psychiatric comorbidities $[1,9,14,64,65]$. Considering there are few effective treatment options available for the management of skin fibrosis, novel therapies such as microRNA (miRNA) modulators are warranted.

The complex process of fibrosis involves the interaction of various cell types, growth factors, and cytokines [75]. A summary of the mechanisms of fibrosis is presented in Figure 1. Persistent injury, infection and inflammation are known triggers of fibrosis [75]. The trigger leads to disruption of endothelial cells in the vasculature, a feature associated with the onset of fibrotic disease [16]. Damaged endothelial cells secrete cytokines to recruit and activate immune cells such as neutrophils, macrophages, T-lymphocytes and B-lymphocytes $[16,75]$. These immune cells release key fibrotic growth factors, identified as transforming growth factor (TGF)-beta, connective tissue growth factor (CTGF) and platelet-derived growth factor (PDGF) [16,75]. TGF-beta1 is a widely recognized factor in organ fibrosis and upregulates the expressions of CTGF and PDGF. The actions of TGF-beta1, CTGF, and PDGF result in the activation and proliferation of fibroblasts and differentiation into myofibroblasts, cells with high proliferative capacity responsible for the excessive synthesis and accumulation of ECM that characterizes fibrosis. Furthermore, myofibroblasts express alpha-smooth muscle actin (alpha-SMA) and contract the matrix [16,75].

MiRNAs have gained the attention of researchers as they may provide a new vantage point for studying the molecular mechanisms associated with skin fibrosis [11,26,34,47,53]. MiRNAs are a class of small, noncoding RNAs that range from 18 to 25 nucleotides in length and modify gene expression by binding to target messenger RNA (mRNA), causing degradation of the target mRNA or inhibiting the translation into proteins $[5,26]$. MiRNAs comprise $1-5 \%$ of genes in the mammalian genome and are involved in various biological processes including cellular proliferation, development, differentiation, growth control, and apoptosis $[4,5,12,26,57]$. Studies have demonstrated the involvement of miRNAs in the fibrosis of several organ systems, including skin, heart, liver, kidney, and lungs [26]. In dermatology, miRNAs regulate skin development and alterations in gene expression have been associated with skin pathologies, such as inflammatory disorders $[60,61]$ and malignant lesions $[24,43,57,77]$. In the past 5 years, there have been at least 137 clinical trials worldwide investigating miRNAs in an array of diseases, including psoriasis, cancers and acute graft versus host disease (from a search of "microRNA" on clinicaltrials.gov). Modulation of miRNAs has potential to address the therapeutic deficiency in the management of skin fibrosis and may emerge a novel treatment modality.

The biogenesis and maturation of miRNAs occurs in multiple steps, starting in the nucleus and concluding in the cytoplasm (Figure 2). In the nucleus, RNA polymerase II transcribes genes encoding miRNA to generate the primary miRNA (pri-miRNA), a large molecule with a stem-loop structure (Figure 2, step 1) $[4,5,53,56]$. The endonuclease Drosha and cofactor DGCR8 asymmetrically cleave the stem-loop structure of pri-miRNA near the base yielding the precursor miRNA (pre-miRNA) (Figure 2, step 2) [5]. The pre-miRNA is then transported to the cytoplasm assisted by export receptor exportin- 5 and the nuclear protein Ran-GTP (Figure 2, step 3) [53].

In the cytoplasm, the endonuclease Dicer and the cofactor transactivation response RNA binding protein (TRBP) process the other end of the miRNA and cleave both strands of the pre-miRNA at the base of the stem loop generating a short duplex structure consisting the mature miRNA strand and the complementary miRNA* strand (Figure 2, step 4) $[5,53,56]$. Helicase unwinds the double-stranded pre-miRNA releasing the single-stranded mature miRNA and the complementary, miRNA* (Figure 2, step 5). In the final step (Figure 2, step 6a and 6b), the 3' end of the mature miRNA strand is loaded onto the RNA-induced silencing complex (RISC) with the help of one of four different Argonaute proteins (Ago 1- 
4) rendering it capable of interacting with targeted mRNAs to modulate gene expression [54]. The miRNA* strand is degraded but may interact with targeted mRNAs in some instances $[5,44,53,56]$.

The key function of miRNAs in skin fibrosis is to regulate the expression of genes involved in the pathogenesis and maintenance of fibrosis. MiRNAs achieve this by interacting with the 3' untranslated region (UTR) of target mRNAs (Figure 2) [53,56]. The interaction between the miRNA and mRNA results in one of two posttranscriptional mechanisms of gene regulation: mRNA degradation or translational repression $[3,53,56]$. The posttranscriptional mechanism utilized is dependent on the level of complementarity between the miRNA and the mRNA; significant complementarity results in mRNA degradation, while more limited complementarity favors translational repression [3].

In this review, we discuss current understanding of the role of miRNAs in skin fibrosis. We highlight miRNA's role in key skin fibrotic events including: transforming growth factor (TGF)-beta signaling, ECM protein synthesis and degradation, and fibroblast proliferation, differentiation, and derivation from epithelial cells. Finally, we describe the diagnostic and therapeutic significance of miRNAs in the management of skin fibrosis.

\section{Methods}

A review of published literature from January 1990 to present on the role of miRNA in skin fibrosis was performed in May, 2013 (Figure 3). A search of the Medline database using PubMed, EMBASE, Web of Science, Google Scholar and Cochrane databases was conducted utilizing specific keywords or MeSH terms. "Skin fibrosis" was combined with: "microRNA," "miRNA," "microRNA therapy," and "miRNA therapy." Fibrotic skin diseases were identified by comprehensive reviewing of the textbook Dermatology [7] and the following terms were combined with "microRNA" and "miRNA": acral fibrokeratoma, amyloidosis, atypical fibroxanthoma, bleomycininduced skin fibrosis, cutaneous angiofibroma, dermatofibroma, dermatofibroma protuberans, eosinophilia-myalgia syndrome, eosinophilic fasciitis, epithelioid cell histiocytoma, fibroblastic rheumatism, fibroma of the tendon sheath, fibrosarcoma, fibrous hamartoma, graft versus host disease, hypertrophic scars, infantile digital fibroma, infantile myofibromatosis, keloids, lipodermatosclerosis, mixed connective tissue disease, multinucleate cell angiohistiocytoma, nephrogenic systemic fibrosis, nodular fasciitis, porphyria cutanea tarda, restrictive dermopathy, scleredema, scleredema diabeticorum, scleroderma, scleromyxedema, sclerotic fibroma of the skin, stiff skin syndrome, superficial fascial fibromatosis, taxane-induced skin fibrosis, toxic oil syndrome, and Winchester syndrome. The relevant articles that met the following criteria were selected for inclusion: reviews, guidelines, and research studies on miRNA in skin fibrosis. Papers published in a language other than English were excluded.

\section{Results}

Our search resulted in 167 articles (Figure 3). After duplicates were removed, a total of 72 articles were screened. 3 articles were in a language other than English. Of the remaining 69 articles, 27 were irrelevant to skin fibrosis. This resulted in 42 articles that met inclusion criteria and were included in this review: 12 review articles, 26 basic science studies, and 4 clinical studies. 


\section{MiRNA Regulation of Skin Fibrosis}

Several miRNAs are involved in the regulation of key processes that contribute to skin fibrosis, including TGF-beta signaling, ECM deposition, fibroblast proliferation and differentiation, and epithelial to mesenchymal transition or transformation (EMT). Some miRNAs are profibrotic and their upregulation favors these processes contributing to fibrosis, while anti-fibrotic miRNAs inhibit these processes and may be reduced in fibrosis $[26,53,57,71]$. In this section, we discuss key fibrotic processes and regulation by miRNAs (Figures 4). A summary of miRNAs upregulated and downregulated in skin fibrosis is presented in Tables 1 and 2, respectively.

\section{MicroRNA Regulation of Transforming Growth Factor-beta Signaling}

TGF-beta has been implicated in the initiation and maintenance of fibrosis and may interact with miRNAs to elicit these effects. The TGF-beta signaling cascade involves multiple steps (Figure 4): TGF-beta is a soluble mediator and binds to the TGF-beta type II receptor, leading to the recruitment of the TGF-beta type I receptor [62]. The TGF-beta type I receptor conducts the signal through the activation of intracellular Smad2 and Smad3, that bind to Smad4 to form a complex [62]. The Smad complex then regulates the expression of a subset of genes encoding profibrotic factors, such as matrix structural elements $[62,79]$.

MiRNAs are involved at each level of the TGF-beta pathway, targeting TGF-beta protein, receptor, and Smad proteins (Figure 4). MiRNA-29 and miRNA-206 are involved at the beginning of the pathway and lead to reduced expression of TGF-beta protein $[34,49]$. However, in scleroderma, these miRNAs are downregulated and as a result sustain the TGFbeta signaling cascade with an associated increase in collagen synthesis [34,49]. MiRNA-29 negatively regulates type I collagen synthesis and miRNA-206 reduces the expressions of types VI and XXIX collagen [34,49].

Further down the pathway, miRNA-140-5p, let-7g, and miRNA-23b modulate TGF-beta signaling at the level of the receptor, specifically regulating the TGF-beta type II receptor (Figure 4) [34]. MiRNA-140-5p downregulates the activity of the TGF-beta type II receptor while let-7g and miRNA-23b upregulate TGF-beta type II receptor activity [34]. Clinically, let-7g, miRNA-23b, and miRNA-140-5p are associated with scleroderma [34]. Furthermore, miRNA-17-5p and miRNA-20 reduce the expression of the TGF-beta type II receptor and are associated with hypertrophic scars [51].

Other miRNAs are involved in TGF-beta pathway regulation at the level of Smad proteins: MiRNA-145 is hypothesized to target Smad3 mRNA while miRNA-18 and miRNA-146a limit the expression of Smad4 protein (Figure 4) [37,51,78]. Downregulating the expressions of these Smad proteins inhibits the downstream profibrotic effects of the TGF-beta pathway, including ECM protein synthesis [37,78]. The downregulation of miRNA-18 and miRNA-145 are associated with hypertrophic scars and scleroderma, respectively and may represent therapeutic treatment targets for these conditions [51,78].

Unlike other described Smad proteins, Smad7 is a recognized antagonist of the TGF-beta profibrotic effects (Figure 4) [79]. Some miRNAs exploit this avenue in the regulation of skin fibrosis: TGF-beta signaling upregulates miRNA-21 transcription and miRNA-21 in turn reduces the expression of Smad7 releasing the inhibition on the TGF-beta pathway to create a feedforward loop (Figure 4) [79]. MiRNA-503 is hypothesized to function similarly to miRNA-21 by reducing Smad7 expression [78]. We hypothesize that clarifying differences in the roles and mechanisms of miRNA-21 and miRNA-503 in modulating TGFbeta signaling may reveal how these pathways can be harnessed therapeutically in the management of skin fibrosis. 
Several other miRNAs have also been associated with TGF-beta signaling, although the exact levels of regulation have not been elucidated. Such miRNAs include miRNA-4269, miRNA-382, miRNA-203, and miRNA-205 and are hypothesized to regulate collagen synthesis in keloids [36]. One study showed that levels of miRNA-4269 and miRNA-382 are increased in keloid tissue, while levels of miRNA-203 and miRNA-205 are decreased [36]. Therefore, we envision that modulating miRNAs in keloids may result in new therapeutic modalities for a difficult to treat disease.

The TGF-beta pathway interacts with miRNA-150 and miRNA-196a in collagen synthesis $[20,21]$ and is also involved in fibroblast proliferation (via miRNA-21 and miRNA-31), differentiation (via miRNA-146a), and EMT (via miRNA-21 and miRNA-200) $[31,46,52,71]$. Considering the key involvement of TGF-beta signaling in skin fibrotic processes, targeting associated miRNAs may prove invaluable in halting skin fibrosis. Therapies may be designed to modify the different levels of the pathway. MiRNAs that are downregulated in skin fibrosis may be replaced, while those that are upregulated may be reduced.

\section{MicroRNA Regulation of Extracellular Matrix Synthesis and Degradation}

Excessive ECM protein deposition is a key pathogenic feature of skin fibrosis. ECM is composed predominantly of collagen, and other proteins including fibrillin, fibronectin, and elastin. Increased ECM deposition is a result of increased ECM protein synthesis and/or decreased degradation. ECM degradation occurs predominantly from the actions of matrix metalloproteinases (MMPs). When homeostasis between matrix synthesis and degradation is lost, skin fibrosis may result. Various miRNAs modulate skin fibrosis by regulating ECM protein synthesis and degradation.

MiRNA-29 is a key negative regulator of ECM protein synthesis (Figure 4) [11,30,49,78]. MiRNA-29 has been studied in scleroderma patients and was found to be consistently downregulated in patient-derived skin fibroblasts [41]. MiRNA-29 directly targets type I collagen mRNA and is proposed to be a downstream mediator of the following profibrotic molecules: TGF-beta, platelet-derived growth factor (PDGF)-beta, and interleukin (IL)-4 $[41,49]$. One study found that treatment of normal skin fibroblasts with TGF-beta, PDGFbeta and IL-4 induced a scleroderma-like phenotype and downregulated miRNA-29 to an extent similar to that observed in scleroderma fibroblasts [41]. These results suggest TGFbeta, PDGF-beta and IL-4 mediate skin fibrosis in part by downregulating miRNA-29 expression. Apart from type I collagen, miRNA-29 participates in the regulation of other ECM proteins (including fibrillin and elastin) by repressing the TGF-beta, Wnt/beta-catenin, nuclear factor-kappa B (NF- $\kappa$ B) and mitogen activated protein kinase (MAPK) profibrotic signaling pathways $[19,49]$. Considering that miRNA-29 is a critical suppressor of ECM proteins, the reintroduction of miRNA29 to fibrotic skin using mimics or viral vectors could be a potent anti-fibrotic strategy $[11,49]$.

In addition to miRNA-29, several other miRNAs negatively regulate collagen expression and are downregulated in fibrotic skin diseases: let-7a, miRNA-133a, and miRNA-150 in scleroderma; and miRNA-7, miRNA-26a, miRNA-129-5p, miRNA-133b, and miRNA-196a in scleroderma and keloids (Figure 4) [15,20,21,27,29,34,38]. These miRNAs target collagen directly with the exception of miRNA-150 [15,20,21,27,29,34,38]. Downregulation of miRNA-150 leads to the overexpression of integrin beta-3 and can activate TGF-beta signaling; activated TGF-beta signaling stimulates Smad3 phosphorylation inducing the transcription of collagen and the development and maintenance of skin fibrosis [20]. Evidence suggests that miRNAs may have important clinical applications and may modify disease management in practice. Studies found that patients with lower serum levels of let-7a and miRNA-150 had a higher ratio of diffuse to localized scleroderma, and higher 
skin thickness as assessed by the modified Rodnan skin score (MRSS) [21,38]. Furthermore, serum concentrations of miRNA-7 and miRNA-196a inversely correlated with duration of scleroderma, such that those with a longer history of the disease had lower levels of the miRNAs $[15,20]$. These findings suggest miRNAs may also be valuable in monitoring and evaluating disease progression longitudinally. Serum miRNAs may be particularly useful in early diagnosis before the clinical features of scleroderma have fully developed, allowing early treatment [21].

MiRNA-92a takes a different approach and regulates ECM degradation (Figure 4). To maintain homeostasis in ECM deposition, collagen is degraded by MMP-1 [58].

Scleroderma has been associated with the downregulation of MMP-1 resulting in excessive collagen accumulation [58]. MiRNA-92a is hypothesized to mediate MMP-1

downregulation in scleroderma and likely contributes to skin fibrosis in the disease (Figure 4) [58]. One study found that miRNA-92a was upregulated in the serum and skin fibroblasts of scleroderma patients [58]. Clarifying the role of miRNA-92a in scleroderma may present a therapeutic avenue in the management of the disease [58].

Since ECM deposition is a key feature of skin fibrosis and is modulated by several miRNAs, targeting associated miRNAs may be worthwhile in the management of fibrotic skin disorders. Identification of other miRNAs that modulate ECM deposition may also expand potential therapeutic targets and allow for monitoring of disease progression and response to therapy.

\section{MicroRNA Regulation of Fibroblast Proliferation, Differentiation, and Derivation from Epithelial Cells}

In the skin, fibroblasts play a crucial role in ECM protein synthesis and differentiate into myofibroblasts with high proliferative capacity and ability to synthesize large numbers of ECM molecules. Although fibroblasts are considered to be derived from mesenchymal cells, they may have non-mesenchymal precursors as epithelial cells can differentiate into fibroblasts in a process termed "epithelial to mesenchymal transition or transformation" (EMT) [31]. Our understanding of the role of EMT in skin fibrosis is evolving and EMT is suggested to be involved in the pathogenesis of scleroderma [50,74]. MiRNAs modulate skin fibrosis by regulating the following key fibroblastic processes: proliferation, differentiation, and EMT.

Fibroblast proliferation is a target of both miRNA-21 and miRNA-31. MiRNA-21 elicits this effect by inhibiting Sprouty1, a recognized antagonist of fibroblast proliferation (Figure 4). Sprouty 1 achieves its inhibitory role on fibroblasts by blocking extracellular receptor kinase (ERK) and MAPK, two pathways implicated in fibroblast proliferation (Figure 4) [31,71]. Therefore, miRNA-21 indirectly releases the inhibition on the ERK and MAPK pathways resulting in increased fibroblasts. The mechanism via miRNA-31 promotes fibroblast proliferation has not been elucidated and presents opportunity for further research [78].

Fibroblast differentiation into myofibroblasts is negatively regulated by miRNA-146a in the skin $[37,78]$. It is proposed that miRNA-146a carries out this function by repressing the translation of Smad4 proteins in fibroblasts (Figure 4) [22,37,78]. Conversely, it was shown that TGF-beta upregulates the expression of miRNA-146 [37]. This interaction suggests that miRNA-146a is a critical modulator of TGF-beta signaling and uses this effect to regulate fibroblast differentiation [37].

EMT is regulated by interactions of TGF-beta with miRNA-21 (Figure 4) [31]. TGF-beta upregulates miRNA-21 and miRNA-21 in turn regulates the expression of the phosphatase and tensin homolog (PTEN) gene [31]. PTEN is a recognized inhibitor of EMT and is 
targeted and inhibited by miRNA-21 (Figure 4) [46,52]. By blocking the expression of PTEN, miRNA-21 releases the inhibition on EMT resulting in an increase in the number of fibroblasts derived from epithelial cells [31].

The miRNA-200 family may also be involved in EMT and is composed of five members some of which are numbered outside of the miRNA-200 range: miRNA-200a, miRNA-200b, miRNA-200c, miRNA-141, and miRNA-429 [32]. Although the role of the miRNA-200 family in the skin has not been firmly established, miRNA-200b and miRNA-200c have been found downregulated in keloids [36]. MiRNA-200 is associated with EMT inhibition via TGF-beta interactions in other organ systems [32]. In the kidney, TGF-beta signaling activates mesenchymal transcription factors, Zeb1 and Zeb2, to induce EMT (Figure 4). However miRNA-200 suppresses the expression of these transcription factors $[44,48,63]$. MiRNA-200 has been suggested to also repress TGF-beta directly in the kidney [44]. We hypothesize that miRNA-200 may function similarly in the skin contributing to fibrosis. Confirming the role of miRNA-200 in keloids may improve understanding of the pathogenesis of cutaneous fibrotic diseases.

Targeting miRNAs involved in fibroblast proliferation, differentiation, and EMT is another avenue in halting skin fibrosis since fibroblasts are the major cells involved in ECM deposition. Thus, clarifying the mechanisms of identified miRNAs and discovery of new miRNAs may create a potential therapeutic approach in the management of fibrotic skin diseases.

\section{Clinical Applications of MiRNAs in Skin Fibrosis}

MiRNAs have important clinical applications in skin fibrosis. The discovery that miRNAs are detectable in serum, plasma, and other bodily fluids, and are relatively stable, suggests miRNAs may serve as valuable biomarkers to monitor disease progression and response to treatment. It is demonstrated that miRNAs in plasma are protected from degradation by inclusion in lipid or lipoprotein complexes. Characteristic alterations in the serum or plasma miRNA profiles in disease states could be exploited as novel biomarkers. The clinical utility of miRNAs as disease biomarkers has been studied in skin malignancy and has gained the attention of cutaneous fibrosis researchers. MiRNAs regulating skin fibrotic processes, such as let-7a, miRNA-7, miRNA-196a, and miRNA-150, have been detected in decreased levels in the serum of patients with scleroderma and affirm the potential of miRNA as a marker of the disease $[3,10,18,23,24,42,69]$. One study also demonstrated that serum levels of miRNA-142-3p are significantly higher in scleroderma patients [39]. In addition to the skin, miRNAs hold diagnostic promise in liver and renal fibrosis, asthma, pancreatic, colorectal, and thyroid cancer, cardiovascular diseases, traumatic brain injuries and infections. The broad applicability of miRNAs may revolutionize diagnosis in several medical fields and may allow early diagnosis and treatments leading to improved patient outcome.

Evidence suggests miRNAs may have therapeutic significance and may potentially modulate skin fibrosis. Development of miRNA-targeted therapies for the management of skin fibrosis may be channeled into one of two categories: increasing the expression of antifibrotic miRNAs or reducing the expression of profibrotic miRNAs. Either approach may help in regulating the key skin fibrotic processes. The skin is an ideal target for gene therapy as it is readily accessible.

In combating skin fibrosis, anti-fibrotic miRNAs may be upregulated with the use of miRNA mimics or viral vectors [3,25]. Mimics are synthetic short double-stranded oligonucleotides, consisting of a guide strand and a passenger strand $[3,17]$. The guide strand has the same nucleotide sequence as the mature miRNA and is incorporated into the RISC complex $[3,17]$. The passenger strand is equivalent to miRNA* and complementary to 
the mature sequence [3,17]. Efficacy of let-7a mimic was successfully tested in vivo in a BALB/cAJcl mouse model of bleomycin-induced skin fibrosis [38]. Let-7a oligonucleotides were administered percutaneously into the abdominal cavity and resulted in a significant increase in let-7a levels in the skin, with an associated improvement in skin fibrosis [38]. Mimics are hypothesized to be an effective strategy of miRNA reintroduction into tissues as they carry the same sequence as the naturally occurring equivalent and are expected to target the same genes [2]. Given that the target miRNA is expressed physiologically, mimics are not anticipated to induce adverse effects as the cellular pathways modulated by mimics are already regulated by endogenous miRNAs [2].

MiRNA expression can also be increased with the use of lentiviral (LV), adenoviral (AV), or adeno-associated viral (AAV) vectors with built-in miRNA precursor constructs $[3,67]$. The choice of viral vector is usually dependent on whether long-term or transient expression is desired [13]. LVs integrate into the host genome and appear to be more suited for longterm miRNA expression. LVs have been found effective for cutaneous gene transfer and long-term gene expression in fibroblasts $[13,45,59]$. The LV strategy was used to overexpress miRNA-16 in an in vitro model of liver fibrosis and resulted in decreased proliferation of hepatic stellate cells, the key cells involved in liver fibrosis [19]. However, LVs are restricted by their ability to primarily infect non-dividing cells [67]. AVs have the advantage of being able to efficiently infect both dividing and non-dividing cells [13]. The major reservation for the use of AVs is the cytotoxicity of viral proteins triggering host immune response and local inflammation [13]. Since AVs do not integrate into the host genome, AVs may be useful when temporary miRNA expression is needed. The AV technique was used in vitro to overexpress miRNA-375 in alveolar epithelial cells [73]. Downregulation of miRNA-375 has been detected in idiopathic pulmonary fibrosis and overexpression of miRNA-375 may be therapeutic in the disease [73]. The nonpathogenicity of AAVs makes them another attractive option for miRNA re-introduction [67]. AAV-2 type is prevalent in human population and often neutralized by antibodies [67]. AAVs infect both dividing and non-dividing cells and may integrate into host genome. The AAV strategy has been successfully demonstrated in vivo to replace cardiac-expressed miRNA-1 in rats and led to a significant reduction of myocardial fibrosis [28]. Therefore, AAVs may represent the ideal vector for the treatment of skin fibrosis, as it has been successfully used as an anti-fibrotic therapy in animal models and does not cause disease in humans. However, human antibodies against AAVs may limit the effectiveness of AAVs.

Another possible approach in the management of skin fibrosis is to downregulate the expression of profibrotic miRNAs using anti-miRNAs, sponges, erasers, and masks and has been successfully demonstrated in other organ system models. Some of the applications of these methods are listed in Figure 5. Anti-miRNAs (Figure 5a) are synthetic oligonucleotides that are complementary and bind to target miRNAs inhibiting the activity of the miRNA [3]. One study showed that direct injection of anti-miRNA against miRNA-21 into the dermis of wounded mice impaired collagen deposition in vivo [72]. Therefore antagonizing miRNA-21 may be therapeutic in the management of skin fibrosis. Sponges (Figure 5b) are competitive inhibitors of miRNAs containing several, tandem binding sites to the target miRNA. The binding sites of a sponge are specific to the seed region (miRNA nucleotides $2-7$, the major specificity determinant for target recognition). Therefore sponges may be used to block a whole family of related miRNAs possessing a common seed region [6]. Sponges also have a bulge at the miRNA-binding site preventing cleavage by the RISC component, Ago2 [3]. MiRNA erasers (Figure 5c) are similar to sponges, except that erasers utilize two copies of the perfectly complementary antisense sequence of the miRNA [3]. Mask (Figure 5d) oligonucleotides do not directly interact with the target miRNA, but instead bind to the miRNA target sequence of the mRNA, preventing the miRNA/mRNA interaction [17,72]. Masks are anticipated to have few adverse effects 
since they interact directly with the mRNA permitting, the miRNA to regulate other cellular processes. Anti-miRNAs, sponges, erasers and masks are complementary to each other and we believe could be used to serve different anti-fibrotic modulatory purposes: since antimiRNAs bind to a specific miRNA, they may be useful when the goal is to block the activity of a single miRNA; sponges and erasers bind to seed regions of miRNAs and may be the ideal option for blocking the activities of a family of related miRNAs containing a common seed region; masks bind directly to the mRNA preventing the miRNA from binding to the mRNA and may be suitable for modifying a specific target gene of the miRNA allowing the miRNA to regulate other genes.

MiRNA-targeted therapies may potentially aid the management of skin fibrosis since regulating a single miRNA could effectively modify a group of functionally related genes in a pathway [3]. MiRNAs can also be effectively modified in vitro as well as in vivo [3]. There are two miRNA modulators currently in clinical trials. This represents a new field of study, as no other miRNA modulators have been evaluated previously. As these two miRNA modulators have not completed clinical trials, there is no knowledge of potential cost.

The first human clinical trial of a miRNA-targeted drug, miravirsen, concluded the phase I and IIa clinical trials. Miravirsen is an anti-miRNA against liver-expressed miRNA-122 and is being evaluated for the treatment of hepatitis C [35]. MiRNA-122 is the most abundant miRNA in hepatocytes and is involved in the replication of hepatitis $C$ virus [35]. The drug was administered subcutaneously once a week for 5 weeks and was well tolerated with no dose-limiting toxicities [35]. Preliminary results also reveal that the drug may be efficacious for hepatitis $\mathrm{C}$ as there was a dose dependent reduction in plasma levels of viral RNA with miravirsen treatment [35]. There was no sign of drug resistance [35].

The second ongoing clinical trial is evaluating the drug, MRX34, a mimic of miRNA-34 for the treatment of primary liver cancer or metastatic cancer with liver involvement. This trial is currently recruiting for a phase I study and is projected to conclude in August, 2014. MRX34 will be administered intravenously twice a week for 3 weeks, followed by a week off. This trial should elucidate the safety and dose-limiting toxicity of MRX34. These reports suggest miRNA modulators could emerge as a new class of drugs and may be an attractive option for the treatment of skin fibrosis, a group of conditions with limited treatment options. Perhaps in the future, topical miRNA modulators may be of substantive use in dermatology.

Since miRNAs have diverse roles and may regulate physiological pathways, potential challenges in the development of miRNA therapies for the treatment of skin fibrosis include side effects from interactions with non-target miRNA [53]. Synthetic oligonucleotides are also prone to renal filtration and cleavage by serum endonucleases, contributing to chemical instability, although this can be improved by chemically altering synthetic oligonucleotides using 2'-0-methyl group-modification, 2'-0-methoxyethyl-modification, and locked nucleic acid (LNA)-modification [3,17,53,75]. Efficient delivery of oligonucleotides is another obstacle that has been encountered in the translation of miRNA-based therapies into the clinic [53]. However, the accessibility of the skin tissue may allow local administration of oligonucleotides and increases the feasibility of miRNA therapeutics in treating fibrotic skin diseases [53]. In light of the success of the first human miRNA clinical trials, we anticipate that miRNA-targeted therapeutics may transform the management of fibrotic skin disorders by physicians. 


\section{Conclusion}

The recently identified miRNAs regulate gene expression and modulate key processes involved in skin fibrosis: TGF-beta signaling, ECM deposition, fibroblast proliferation and differentiation, and EMT. Some miRNAs are profibrotic and their upregulation stimulates fibrosis, while others are anti-fibrotic and may be downregulated in fibrosis. In treating skin fibrosis, therapies may be directed towards upregulating anti-fibrotic miRNAs or downregulating profibrotic miRNAs. There are few effective treatment options for cutaneous fibrotic diseases. We believe that miRNA modulators have the potential to contribute significantly to the management of cutaneous fibrotic diseases and are worthy of future investigation.

\section{Acknowledgments}

Funding Source:

The project described was supported by the National Center for Advancing Translational Sciences, National Institutes of Health, through grant number UL1 TR000002 and linked award TL1 TR000133.

The project described was supported by the National Center for Advancing Translational Sciences, National Institutes of Health, through grant number UL1 TR000002 and linked award KL2 TR000134.

Research reported in this publication was supported by the National Institute Of Allergy And Infectious Diseases of the National Institutes of Health under Award Number R33AI080604.

The content is solely the responsibility of the authors and does not necessarily represent the official views of the National Institutes of Health.

\section{Abbreviations}

$\begin{array}{ll}\text { Ago } & \text { Argonuate } \\ \text { AAV } & \text { Adeno-associated viral vector } \\ \text { AV } & \text { Adenoviral vector } \\ \text { CTGF } & \text { Connective tissue growth factor } \\ \text { ECM } & \text { Extracellular matrix } \\ \text { EMT } & \text { Epithelial to mesenchymal transition or transformation } \\ \text { ERK } & \text { Extracellular receptor kinase } \\ \text { IL } & \text { Interleukin } \\ \text { LNA } & \text { Locked nucleic acid } \\ \text { LV } & \text { Lentiviral vector } \\ \text { miRNA } & \text { MicroRNA } \\ \text { MAPK } & \text { Mitogen activated protein kinase } \\ \text { MRSS } & \text { Modified Rodnan skin score } \\ \text { NF- } \text { KB; } & \text { Nuclear factor-kappa B } \\ \text { PDGF } & \text { Platelet-derived growth factor } \\ \text { pre-miRNA } & \text { Precursor-miRNA } \\ \text { pri-miRNA } & \text { Primary-miRNA }\end{array}$


PTEN Phosphatase and tensin homolog

RISC RNA-induced silencing complex

SMA Smooth muscle actin

TGF Transforming growth factor

UTR Untranslated region

\section{References}

1. Abdullah A, Blakeney P, Hunt R, Broemeling L, Phillips L, Herndon DN, Robson MC. Visible scars and self- esteem in pediatric patients with burns. The Journal of burn care \& rehabilitation. 1994; 15(2):164-168. [PubMed: 8195258]

2. Bader A, Lorenz K, Richter A, Scheffler K, Kern L, Ebert S, Giri S, Behrens M, Dornseifer U, Macchiarini P, Machens HG. Interactive role of trauma cytokines and erythropoietin and their therapeutic potential for acute and chronic wounds. Rejuvenation research. 2011; 14(1):57-66. [PubMed: 21329452]

3. Banerjee J, Sen CK. MicroRNAs in skin and wound healing. Methods in molecular biology. 2013; 936:343-356. [PubMed: 23007520]

4. Bartel DP. MicroRNAs: genomics, biogenesis, mechanism, and function. Cell. 2004; 116(2):281297. [PubMed: 14744438]

5. Bartel DP. MicroRNAs: target recognition and regulatory functions. Cell. 2009; 136(2):215-233. [PubMed: 19167326]

6. Batkai S, Thum T. MicroRNAs in hypertension: mechanisms and therapeutic targets. Current hypertension reports. 2012; 14(1):79-87. [PubMed: 22052337]

7. Bolognia, JL.; Jorizzo, JL.; Schaffer, JV. Dermatology 3e. Mosby: St. Louis; 2012.

8. Bowen T, Jenkins RH, Fraser DJ. MicroRNAs, transforming growth factor beta-1, and tissue fibrosis. The Journal of pathology. 2013; 229(2):274-285. [PubMed: 23042530]

9. Brych SB, Engrav LH, Rivara FP, Ptacek JT, Lezotte DC, Esselman PC, Kowalske KJ, Gibran NS. Time off work and return to work rates after burns: systematic review of the literature and a large two-center series. The Journal of burn care \& rehabilitation. 2001; 22(6):401-405. [PubMed: 11761392]

10. Chen X, Ba Y, Ma L, Cai X, Yin Y, Wang K, Guo J, Zhang Y, Chen J, Guo X, Li Q, Li X, Wang W, Zhang Y, Wang J, Jiang X, Xiang Y, Xu C, Zheng P, Zhang J, Li R, Zhang H, Shang X, Gong T, Ning G, Wang J, Zen K, Zhang J, Zhang CY. Characterization of microRNAs in serum: a novel class of biomarkers for diagnosis of cancer and other diseases. Cell research. 2008; 18(10):9971006. [PubMed: 18766170]

11. Cheng J, Wang Y, Wang D, Wu Y. Identification of Collagen 1 as a Post-transcriptional Target of miR-29b in Skin Fibroblasts: Therapeutic Implication for Scar Reduction. The American journal of the medical sciences. 2013; 346(2):98-103. [PubMed: 23221517]

12. Cheng J, Yu H, Deng S, Shen G. MicroRNA profiling in mid- and late-gestational fetal skin: implication for scarless wound healing. The Tohoku journal of experimental medicine. 2010; 221(3):203-209. [PubMed: 20543536]

13. Eming SA, Krieg T, Davidson JM. Gene transfer in tissue repair: status, challenges and future directions. Expert opinion on biological therapy. 2004; 4(9):1373-1386. [PubMed: 15335305]

14. Engrav LH, Heimbach DM, Reus JL, Harnar TJ, Marvin JA. Early excision and grafting vs. nonoperative treatment of burns of indeterminant depth: a randomized prospective study. The Journal of trauma. 1983; 23(11):1001-1004. [PubMed: 6355500]

15. Etoh M, Jinnin M, Makino K, Yamane K, Nakayama W, Aoi J, Honda N, Kajihara I, Makino T, Fukushima S, Ihn H. microRNA-7 down-regulation mediates excessive collagen expression in localized scleroderma. Archives of dermatological research. 2013; 305(1):9-15. [PubMed: 22965811] 
16. Falanga, V.; Iwamoto, S. Fitzpatrick's Dermatology in General Medicine. 8th edition. New York: McGraw-Hill; 2012. Mechanisms of Wound Repair, Wound Healing, and Wound Dressing.

17. Fasanaro P, Greco S, Ivan M, Capogrossi MC, Martelli F. microRNA: emerging therapeutic targets in acute ischemic diseases. Pharmacology \& therapeutics. 2010; 125(1):92-104. [PubMed: 19896977]

18. Gilad S, Meiri E, Yogev Y, Benjamin S, Lebanony D, Yerushalmi N, Benjamin H, Kushnir M, Cholakh H, Melamed N, Bentwich Z, Hod M, Goren Y, Chajut A. Serum microRNAs are promising novel biomarkers. PloS one. 2008; 3(9):e3148. [PubMed: 18773077]

19. Guo Y, Xiao L, Sun L, Liu F. Wnt/beta-catenin signaling: a promising new target for fibrosis diseases. Physiological research/Academia Scientiarum Bohemoslovaca. 2012; 61(4):337-346. [PubMed: 22670697]

20. Honda N, Jinnin M, Kajihara I, Makino T, Makino K, Masuguchi S, Fukushima S, Okamoto Y, Hasegawa M, Fujimoto M, Ihn H. TGF-beta-mediated downregulation of microRNA-196a contributes to the constitutive upregulated type I collagen expression in scleroderma dermal fibroblasts. Journal of immunology. 2012; 188(7):3323-3331.

21. Honda N, Jinnin M, Kira-Etoh T, Makino K, Kajihara I, Makino T, Fukushima S, Inoue Y, Okamoto Y, Hasegawa M, Fujimoto M, Ihn H. miR-150 down-regulation contributes to the constitutive type I collagen overexpression in scleroderma dermal fibroblasts via the induction of integrin beta3. The American journal of pathology. 2013; 182(1):206-216.

22. Hu B, Phan SH. Myofibroblasts. Current opinion in rheumatology. 2013; 25(1):71-77. [PubMed: 23114586]

23. Hunter MP, Ismail N, Zhang X, Aguda BD, Lee EJ, Yu L, Xiao T, Schafer J, Lee ML, Schmittgen TD, Nana-Sinkam SP, Jarjoura D, Marsh CB. Detection of microRNA expression in human peripheral blood microvesicles. PloS one. 2008; 3(11):e3694. [PubMed: 19002258]

24. Igoucheva O, Alexeev V. MicroRNA-dependent regulation of cKit in cutaneous melanoma. Biochemical and biophysical research communications. 2009; 379(3):790-794. [PubMed: 19126397]

25. Ishida M, Selaru FM. miRNA-Based Therapeutic Strategies. Current anesthesiology reports. 2013; 1(1):63-70. [PubMed: 23524956]

26. Jiang X, Tsitsiou E, Herrick SE, Lindsay MA. MicroRNAs and the regulation of fibrosis. The FEBS journal. 2010; 277(9):2015-2021. [PubMed: 20412055]

27. Kajihara I, Jinnin M, Yamane K, Makino T, Honda N, Igata T, Masuguchi S, Fukushima S, Okamoto Y, Hasegawa M, Fujimoto M, Ihn H. Increased accumulation of extracellular thrombospondin-2 due to low degradation activity stimulates type I collagen expression in scleroderma fibroblasts. The American journal of pathology. 2012; 180(2):703-714. [PubMed: 22142808]

28. Karakikes I, Chaanine AH, Kang S, Mukete BN, Jeong D, Zhang S, Hajjar RJ, Lebeche D. Therapeutic cardiac-targeted delivery of miR-1 reverses pressure overload-induced cardiac hypertrophy and attenuates pathological remodeling. Journal of the American Heart Association. 2013; 2(2):e000078. [PubMed: 23612897]

29. Kashiyama K, Mitsutake N, Matsuse M, Ogi T, Saenko VA, Ujifuku K, Utani A, Hirano A, Yamashita S. miR-196a downregulation increases the expression of type I and III collagens in keloid fibroblasts. The Journal of investigative dermatology. 2012; 132(6):1597-1604. [PubMed: 22358059]

30. Kawashita Y, Jinnin M, Makino T, Kajihara I, Makino K, Honda N, Masuguchi S, Fukushima S, Inoue Y, Ihn H. Circulating miR-29a levels in patients with scleroderma spectrum disorder. Journal of dermatological science. 2011; 61(1):67-69. [PubMed: 21129921]

31. Kumarswamy R, Volkmann I, Thum T. Regulation and function of miRNA-21 in health and disease. RNA biology. 2011; 8(5):706-713. [PubMed: 21712654]

32. Lamouille S, Subramanyam D, Blelloch R, Derynck R. Regulation of epithelial-mesenchymal and mesenchymal-epithelial transitions by microRNAs. Current opinion in cell biology. 2013; 25(2): 200-207. [PubMed: 23434068] 
33. Lanford RE, Hildebrandt-Eriksen ES, Petri A, Persson R, Lindow M, Munk ME, Kauppinen S, Orum $H$. Therapeutic silencing of microRNA-122 in primates with chronic hepatitis $\mathrm{C}$ virus infection. Science. 2010; 327(5962):198-201. [PubMed: 19965718]

34. Li H, Yang R, Fan X, Gu T, Zhao Z, Chang D, Wang W. MicroRNA array analysis of microRNAs related to systemic scleroderma. Rheumatology international. 2012; 32(2):307-313. [PubMed: 21052672]

35. Lindow M, Kauppinen S. Discovering the first microRNA-targeted drug. The Journal of cell biology. 2012; 199(3):407-412. [PubMed: 23109665]

36. Liu Y, Yang D, Xiao Z, Zhang M. miRNA expression profiles in keloid tissue and corresponding normal skin tissue. Aesthetic plastic surgery. 2012; 36(1):193-201. [PubMed: 21701945]

37. Liu Z, Lu CL, Cui LP, Hu YL, Yu Q, Jiang Y, Ma T, Jiao DK, Wang D, Jia CY. MicroRNA-146a modulates TGF- beta1-induced phenotypic differentiation in human dermal fibroblasts by targeting SMAD4. Archives of dermatological research. 2012; 304(3):195-202. [PubMed: 21968601]

38. Makino K, Jinnin M, Hirano A, Yamane K, Eto M, Kusano T, Honda N, Kajihara I, Makino T, Sakai K, Masuguchi S, Fukushima S, Ihn H. The downregulation of microRNA let-7a contributes to the excessive expression of type I collagen in systemic and localized scleroderma. Journal of immunology. 2013; 190(8):3905-3915.

39. Makino K, Jinnin M, Kajihara I, Honda N, Sakai K, Masuguchi S, Fukushima S, Inoue Y, Ihn H. Circulating miR-142-3p levels in patients with systemic sclerosis. Clinical and experimental dermatology. 2012; 37(1):34-39. [PubMed: 21883400]

40. Mattes J, Collison A, Plank M, Phipps S, Foster PS. Antagonism of microRNA-126 suppresses the effector function of TH2 cells and the development of allergic airways disease. Proceedings of the National Academy of Sciences of the United States of America. 2009; 106(44):18704-18709. [PubMed: 19843690]

41. Maurer B, Stanczyk J, Jungel A, Akhmetshina A, Trenkmann M, Brock M, Kowal-Bielecka O, Gay RE, Michel BA, Distler JH, Gay S, Distler O. MicroRNA-29, a key regulator of collagen expression in systemic sclerosis. Arthritis and rheumatism. 2010; 62(6):1733-1743. [PubMed: 20201077]

42. Mitchell PS, Parkin RK, Kroh EM, Fritz BR, Wyman SK, Pogosova-Agadjanyan EL, Peterson A, Noteboom J, O'Briant KC, Allen A, Lin DW, Urban N, Drescher CW, Knudsen BS, Stirewalt DL, Gentleman R, Vessella RL, Nelson PS, Martin DB, Tewari M. Circulating microRNAs as stable blood-based markers for cancer detection. Proceedings of the National Academy of Sciences of the United States of America. 2008; 105(30):10513-10518. [PubMed: 18663219]

43. Molnar V, Tamasi V, Bakos B, Wiener Z, Falus A. Changes in miRNA expression in solid tumors: an miRNA profiling in melanomas. Seminars in cancer biology. 2008; 18(2):111-122. [PubMed: 18296065]

44. Ning MS, Andl T. Control by a hair's breadth: the role of microRNAs in the skin. Cellular and molecular life sciences : CMLS. 2013; 70(7):1149-1169. [PubMed: 22983383]

45. Palmer TD, Rosman GJ, Osborne WR, Miller AD. Genetically modified skin fibroblasts persist long after transplantation but gradually inactivate introduced genes. Proceedings of the National Academy of Sciences of the United States of America. 1991; 88(4):1330-1334. [PubMed: 1847517]

46. Parapuram SK, Shi-wen X, Elliott C, Welch ID, Jones H, Baron M, Denton CP, Abraham DJ, Leask A. Loss of PTEN expression by dermal fibroblasts causes skin fibrosis. The Journal of investigative dermatology. 2011; 131(10):1996-2003. [PubMed: 21654839]

47. Pastar I, Khan AA, Stojadinovic O, Lebrun EA, Medina MC, Brem H, Kirsner RS, Jimenez JJ, Leslie C, Tomic-Canic M. Induction of specific microRNAs inhibits cutaneous wound healing. The Journal of biological chemistry. 2012; 287(35):29324-29335. [PubMed: 22773832]

48. Patel V, Noureddine L. MicroRNAs and fibrosis. Current opinion in nephrology and hypertension. 2012; 21(4):410-416. [PubMed: 22622653]

49. Peng WJ, Tao JH, Mei B, Chen B, Li BZ, Yang GJ, Zhang Q, Yao H, Wang BX, He Q, Wang J. MicroRNA-29: a potential therapeutic target for systemic sclerosis. Expert opinion on therapeutic targets. 2012; 16(9):875-879. [PubMed: 22793265] 
50. Postlethwaite AE, Shigemitsu H, Kanangat S. Cellular origins of fibroblasts: possible implications for organ fibrosis in systemic sclerosis. Current opinion in rheumatology. 2004; 16(6):733-738. [PubMed: 15577612]

51. Qu L, Liu A, Zhou L, He C, Grossman PH, Moy RL, Mi QS, Ozog D. Clinical and molecular effects on mmature burn scars after treatment with a fractional $\mathrm{CO}(2)$ laser. Lasers in surgery and medicine. 2012; 44(7):517-524. [PubMed: 22907286]

52. Romano C, Schepis C. PTEN gene: a model for genetic diseases in dermatology. TheScientificWorldJournal. 2012; 2012:252457.

53. Sand M, Gambichler T, Sand D, Skrygan M, Altmeyer P, Bechara FG. MicroRNAs and the skin: tiny players in the body's largest organ. Journal of dermatological science. 2009; 53(3):169-175. [PubMed: 19058951]

54. Satoh M, Chan JY, Ceribelli A, Vazquez del-Mercado M, Chan EK. Autoantibodies to Argonaute 2 (Suantigen). Advances in experimental medicine and biology. 2013; 768:45-59. [PubMed: 23224964]

55. Sayed D, Rane S, Lypowy J, He M, Chen IY, Vashistha H, Yan L, Malhotra A, Vatner D, Abdellatif M. MicroRNA-21 targets Sprouty2 and promotes cellular outgrowths. Molecular biology of the cell. 2008; 19(8):3272-3282. [PubMed: 18508928]

56. Schlauder SM, Ahmad A, Horn TD. Dicer and micro-RNAs in cutaneous disease. Journal of cutaneous pathology. 2009; 36(5):607-610. [PubMed: 19476539]

57. Schneider MR. MicroRNAs as novel players in skin development, homeostasis and disease. The British journal of dermatology. 2012; 166(1):22-28. [PubMed: 21824129]

58. Sing T, Jinnin M, Yamane K, Honda N, Makino K, Kajihara I, Makino T, Sakai K, Masuguchi S, Fukushima S, Ihn H. microRNA-92a expression in the sera and dermal fibroblasts increases in patients with scleroderma. Rheumatology. 2012; 51(9):1550-1556. [PubMed: 22661558]

59. Siprashvili Z, Khavari PA. Lentivectors for regulated and reversible cutaneous gene delivery. Molecular therapy : the journal of the American Society of Gene Therapy. 2004; 9(1):93-100. [PubMed: 14741782]

60. Sonkoly E, Stahle M, Pivarcsi A. MicroRNAs: novel regulators in skin inflammation. Clinical and experimental dermatology. 2008; 33(3):312-315. [PubMed: 18419608]

61. Sonkoly E, Wei T, Janson PC, Saaf A, Lundeberg L, Tengvall-Linder M, Norstedt G, Alenius H, Homey B, Scheynius A, Stahle M, Pivarcsi A. MicroRNAs: novel regulators involved in the pathogenesis of psoriasis? PloS one. 2007; 2(7):e610. [PubMed: 17622355]

62. Tan WQ, Gao ZJ, Xu JH, Yao HP. Inhibiting scar formation in vitro and in vivo by adenovirusmediated mutant Smad4: a preliminary report. Experimental dermatology. 2011; 20(2):119-124. [PubMed: 21255090]

63. Tang O, Chen XM, Shen S, Hahn M, Pollock CA. MiRNA-200b represses transforming growth factor- beta1-induced EMT and fibronectin expression in kidney proximal tubular cells. American journal of physiology Renal physiology. 2013; 304(10):F1266-F1273. [PubMed: 23408168]

64. Thombs BD, Haines JM, Bresnick MG, Magyar-Russell G, Fauerbach JA, Spence RJ. Depression in burn reconstruction patients: symptom prevalence and association with body image dissatisfaction and physical function. General hospital psychiatry. 2007; 29(1):14-20. [PubMed: 17189739]

65. Thombs BD, Notes LD, Lawrence JW, Magyar-Russell G, Bresnick MG, Fauerbach JA. From survival to socialization: a longitudinal study of body image in survivors of severe burn injury. Journal of psychosomatic research. 2008; 64(2):205-212. [PubMed: 18222134]

66. Thum T, Gross C, Fiedler J, Fischer T, Kissler S, Bussen M, Galuppo P, Just S, Rottbauer W, Frantz S, Castoldi M, Soutschek J, Koteliansky V, Rosenwald A, Basson MA, Licht JD, Pena JT, Rouhanifard SH, Muckenthaler MU, Tuschl T, Martin GR, Bauersachs J, Engelhardt S. MicroRNA-21 contributes to myocardial disease by stimulating MAP kinase signalling in fibroblasts. Nature. 2008; 456(7224):980-984. [PubMed: 19043405]

67. Tili E, Michaille JJ, Gandhi V, Plunkett W, Sampath D, Calin GA. miRNAs and their potential for use against cancer and other diseases. Future oncology. 2007; 3(5):521-537. [PubMed: 17927518] 
68. Valastyan S, Reinhardt F, Benaich N, Calogrias D, Szasz AM, Wang ZC, Brock JE, Richardson AL, Weinberg RA. A pleiotropically acting microRNA, miR-31, inhibits breast cancer metastasis. Cell. 2009; 137(6):1032-1046. [PubMed: 19524507]

69. Valenti R, Huber V, Iero M, Filipazzi P, Parmiani G, Rivoltini L. Tumor-released microvesicles as vehicles of immunosuppression. Cancer research. 2007; 67(7):2912-2915. [PubMed: 17409393]

70. Varga, J. Harrison's Principles of Internal Medicine. 18th edition. New York: McGraw-Hill; Systemic Sclerosis (Scleroderma) and Related Disorders.

71. Vettori S, Gay S, Distler O. Role of MicroRNAs in Fibrosis. The open rheumatology journal. 2012; 6:130-139. [PubMed: 22802911]

72. Wang T, Feng Y, Sun H, Zhang L, Hao L, Shi C, Wang J, Li R, Ran X, Su Y, Zou Z. miR-21 regulates skin wound healing by targeting multiple aspects of the healing process. The American journal of pathology. 2012; 181(6):1911-1920. [PubMed: 23159215]

73. Wang Y, Huang C, Reddy Chintagari N, Bhaskaran M, Weng T, Guo Y, Xiao X, Liu L. miR-375 regulates rat alveolar epithelial cell trans-differentiation by inhibiting Wnt/beta-catenin pathway. Nucleic acids research. 2013; 41(6):3833-3844.

74. Wei J, Bhattacharyya S, Tourtellotte WG, Varga J. Fibrosis in systemic sclerosis: emerging concepts and implications for targeted therapy. Autoimmunity reviews. 2011; 10(5):267-275. [PubMed: 20863909]

75. Wynn TA, Ramalingam TR. Mechanisms of fibrosis: therapeutic translation for fibrotic disease. Nature medicine. 2012; 18(7):1028-1040.

76. Xiao J, Yang B, Lin H, Lu Y, Luo X, Wang Z. Novel approaches for gene-specific interference via manipulating actions of microRNAs: examination on the pacemaker channel genes HCN2 and HCN4. Journal of cellular physiology. 2007; 212(2):285-292. [PubMed: 17516552]

77. Zhang L, Huang J, Yang N, Greshock J, Megraw MS, Giannakakis A, Liang S, Naylor TL, Barchetti A, Ward MR, Yao G, Medina A, O'Brien-Jenkins A, Katsaros D, Hatzigeorgiou A, Gimotty PA, Weber BL, Coukos G. microRNAs exhibit high frequency genomic alterations in human cancer. Proceedings of the National Academy of Sciences of the United States of America. 2006; 103(24):9136-9141.

78. Zhu H, Li Y, Qu S, Luo H, Zhou Y, Wang Y, Zhao H, You Y, Xiao X, Zuo X. MicroRNA expression abnormalities in limited cutaneous scleroderma and diffuse cutaneous scleroderma. Journal of clinical immunology. 2012; 32(3):514-522. [PubMed: 22307526]

79. Zhu H, Luo H, Li Y, Zhou Y, Jiang Y, Chai J, Xiao X, You Y, Zuo X. MicroRNA-21 in Scleroderma Fibrosis and its Function in TGF-beta- Regulated Fibrosis-Related Genes Expression. Journal of clinical immunology. 2013; 33(6):1100-1109. [PubMed: 23657402] Related articles recently published in Archives of Dermatological Research (selected by the journal's editorial staff):

80. Beyer C, Dees C, Distler JH. Morphogen pathways as molecular targets for the treatment of fibrosis in systemic sclerosis. Arch Dermatol Res. 2013; 305:1-8. [PubMed: 23208311] 


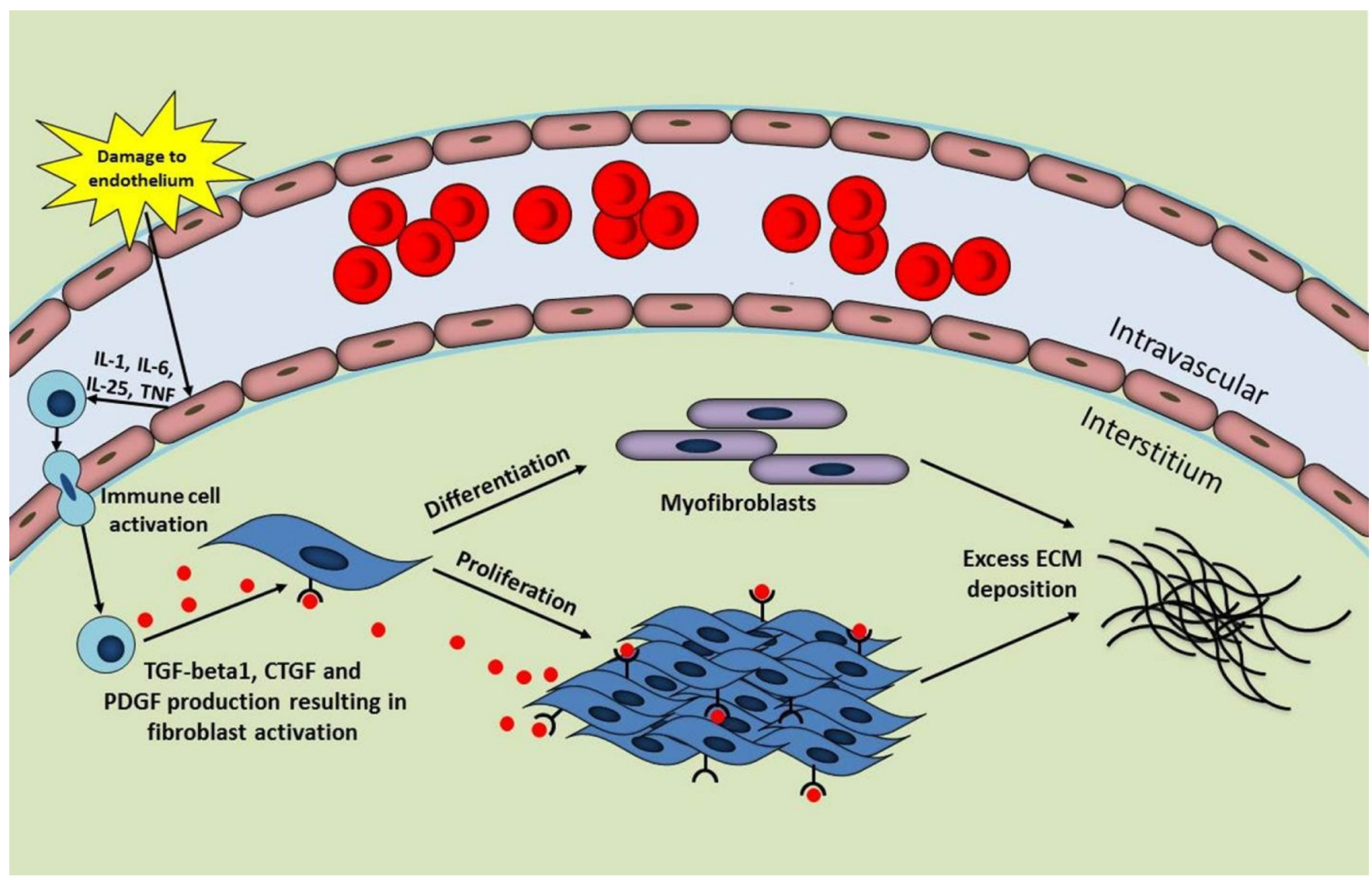

Fig. 1.

Overview of fibrosis. Fibrosis is triggered by an insult such as damage to the endothelial cells in the vasculature. These damaged endothelial cells secrete cytokines resulting in the recruitment of immune cells. Immune cells produce transforming growth factor (TGF)beta1, connective tissue growth factor (CTGF), and platelet-derived growth factor (PDGF) leading to fibroblast activation, proliferation and differentiation into myofibroblasts. The downstream effect is excessive extracellular matrix (ECM) synthesis and deposition by fibroblasts and myofibroblasts, a hallmark feature of fibrosis.

IL, interleukin; TNF, tumor necrosis factor 


\section{EXTRACELLULAR ENVIRONMENT}

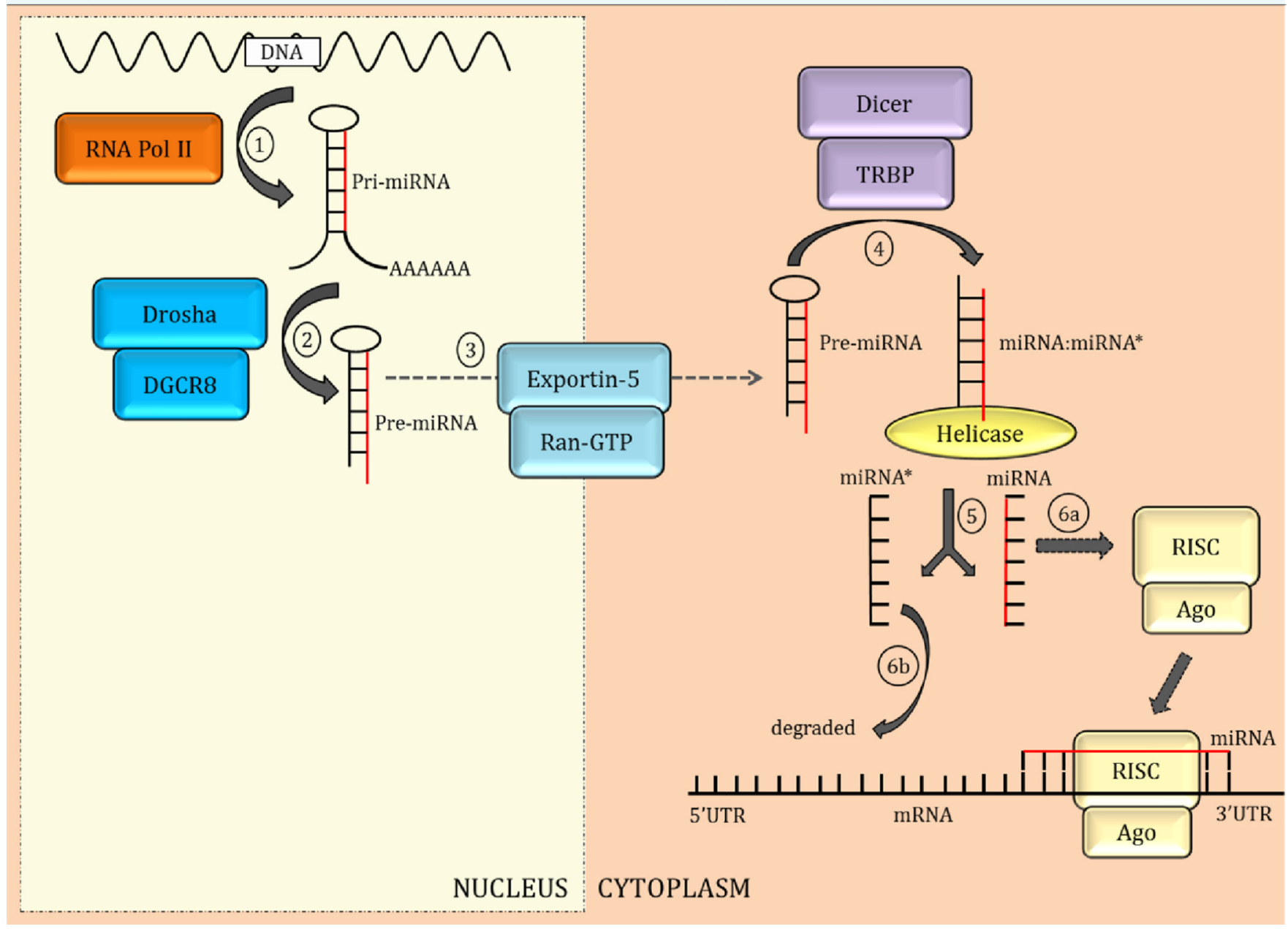

Fig. 2.

MicroRNA (miRNA) biogenesis and maturation. MiRNA biogenesis occurs in multiple steps in the nucleus and cytoplasm. 1) In the nucleus, miRNA genes are transcribed by RNA polymerase (Pol) II to generate primary (pri)-miRNA. 2) Drosha and cofactor DGCR8 cleave the pri-miRNA to produce the precursor (pre)-miRNA. 3) Receptor exportin-5 and RanGTP transport the pre-miRNA to the cytoplasm. 4) Pre-miRNA is processed by Dicer and cofactor TRBP releasing a duplex molecule. 5) Helicase unwinds the duplex releasing the mature miRNA strand and the complementary miRNA*.6a) The mature miRNA strand is loaded onto the RNA-induced silencing complex (RISC) complex with the help of Argonaute (Ago) proteins; the mature miRNA is then capable of interacting with the 3' untranslated region (UTR) of target mRNA. 6b) The miRNA* strand is degraded but may interact with targeted mRNAs in some instances. 


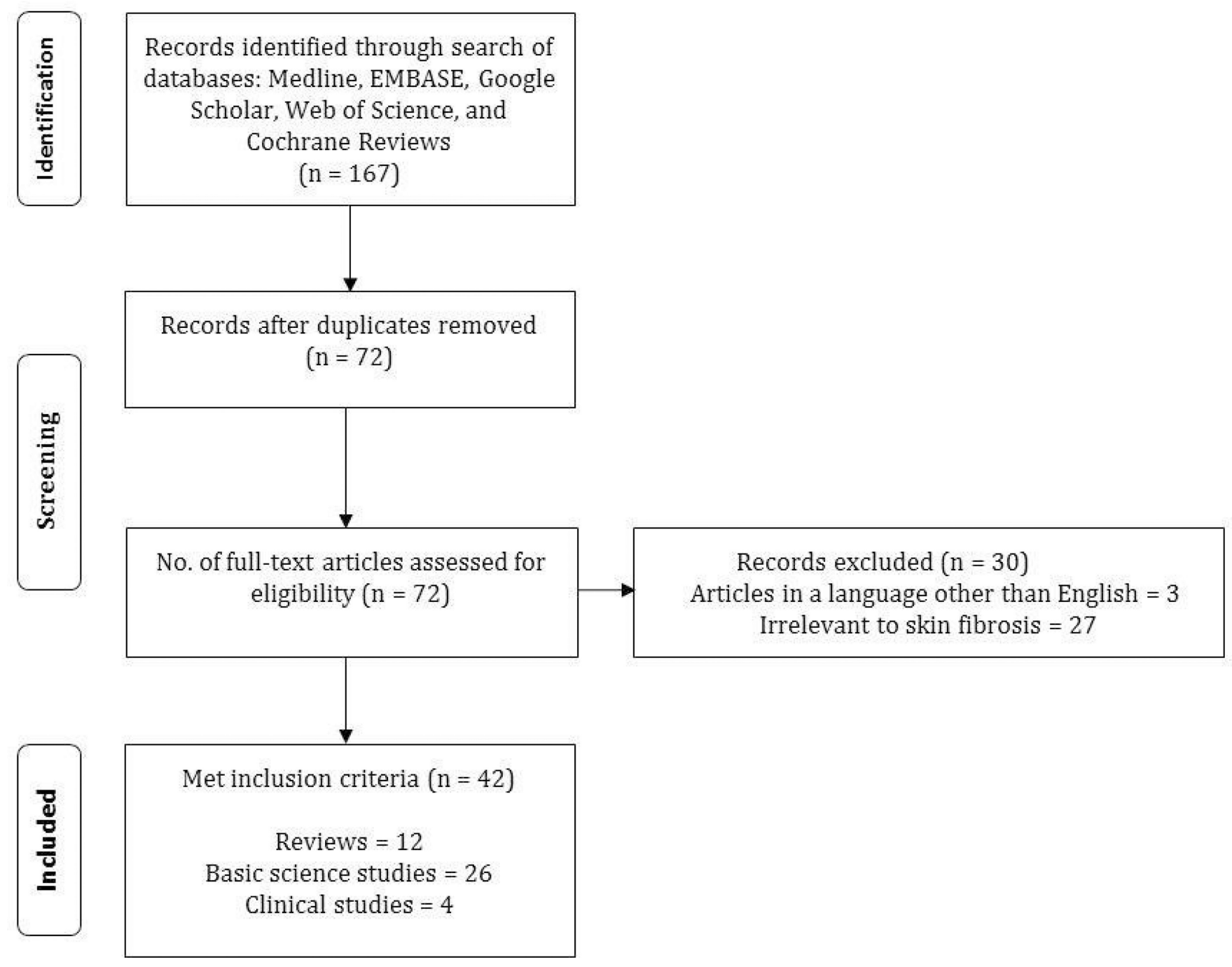

Fig. 3.

Literature search. Illustration of the literature review method and results employed in this article. 


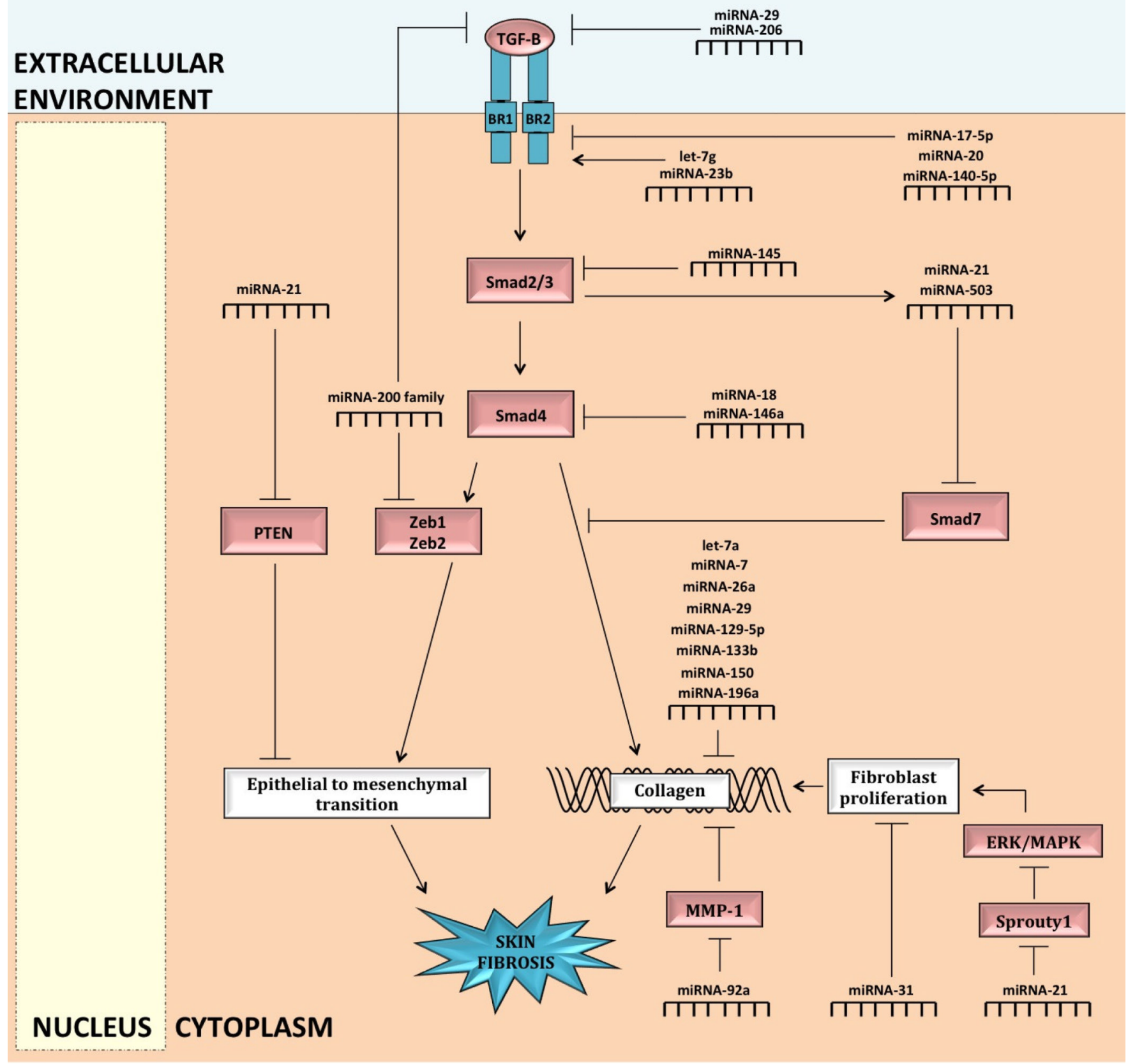

Fig. 4.

MiRNA regulation of skin fibrosis in epithelial and fibroblast cells. MiRNA-21 and miRNA-200 modulate skin fibrosis by interacting with transforming growth factor (TGF)beta signaling to regulate the transition of the epithelial cell into fibroblast cell (epithelial-tomesenchymal transition or transformation, or EMT). MiRNA-200 inhibits PTEN to promote EMT. MiRNA-200 inhibits the transcription factors, Zeb1 and Zeb2, to antagonize EMT; miRNA-200 is also suggested to inhibit TGF-beta directly. Transforming growth factor (TGF)-beta interacts with the type I (BR1) and type II (BR2) receptors, leading to activation of intracellular Smad2 and Smad3. Smad2 and Smad3 form a complex with Smad4 and regulate the expression of collagen. Smad7 is a recognized antagonist of TGF-beta profibrotic effects. Various miRNAs modulate skin fibrosis by regulating the TGF-beta 
signaling pathway, directly regulating collagen synthesis and degradation, and modulating fibroblast proliferation.

MMP, matrix metalloproteinase; MAPK, mitogen activated protein kinase; ERK, extracellular receptor kinase 

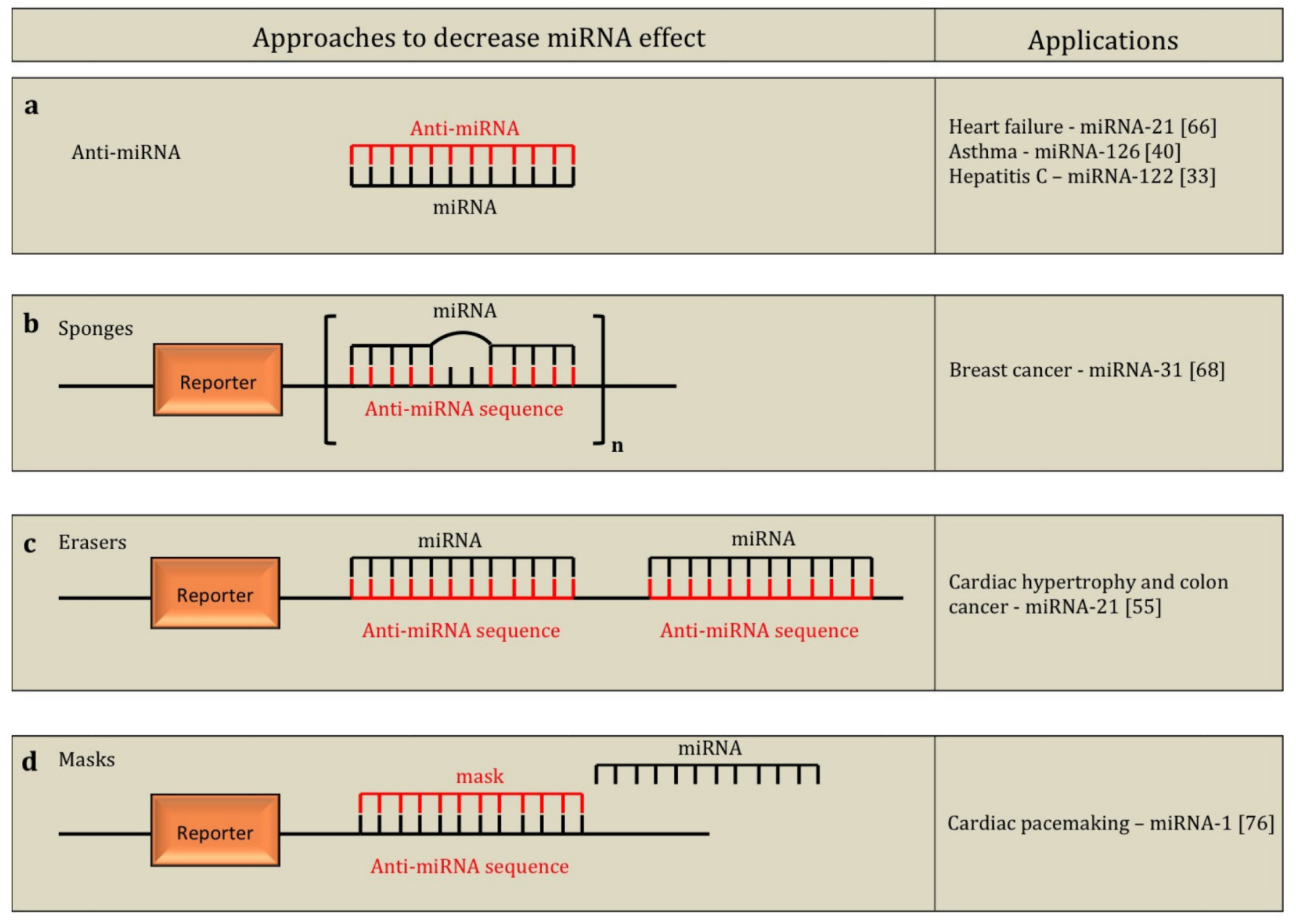

Fig. 5.

Illustration of the principles behind anti-miRNA, sponges, erasers, and masks to decrease miRNA effect and applications in various disease states. Anti-miRNAs (a) are synthetic oligonucleotides with complementary sequence to target miRNAs. Sponges (b) are competitive inhibitors of miRNAs containing several, tandem binding sites to the target miRNA - sponges have a bulge at the miRNA binding site to prevent cleavage. Erasers (c) are similar to sponges, except that erasers utilize two copies of the perfectly complementary antisense sequence of the miRNA. Masks (d) bind to the miRNA target sequence of the messenger RNA (mRNA), preventing the miRNA, mRNA interaction. 
Table 1

MiRNAs upregulated in skin fibrosis

\begin{tabular}{|c|c|c|c|c|}
\hline MicroRNA & $\begin{array}{c}\text { Associated } \\
\text { fibrotic skin } \\
\text { diseases }\end{array}$ & Notable targets & $\begin{array}{l}\text { Key skin fibrotic } \\
\text { processes }\end{array}$ & References \\
\hline \multirow[b]{2}{*}{ let-7g } & \multirow[b]{2}{*}{ Scleroderma } & TFG $\beta R$ & TGF- $\beta$ signaling & \multirow[b]{2}{*}{ [34] } \\
\hline & & $\begin{array}{c}\text { Collagen types I, V } \\
\text { and XXI }\end{array}$ & ECM synthesis & \\
\hline \multirow{3}{*}{ miRNA-21 } & \multirow{3}{*}{ Scleroderma } & Smad7 & TGF- $\beta$ signaling & {$[78,79]$} \\
\hline & & Sprouty1 & Fibroblast proliferation & {$[31,71]$} \\
\hline & & PTEN & $\begin{array}{c}\text { Epithelial to } \\
\text { mesenchymal transition }\end{array}$ & {$[31,52]$} \\
\hline \multirow{2}{*}{ miRNA-23b } & \multirow{2}{*}{ Scleroderma } & TFG $\beta 2 R$ & TGF- $\beta$ signaling & [34] \\
\hline & & Collagen type $\mathrm{V}$ & ECM synthesis & [34] \\
\hline miRNA-31 & Scleroderma & Fibroblasts & Fibroblast proliferation & [78] \\
\hline miRNA-92a & Scleroderma & MMP & ECM degradation & [58] \\
\hline miRNA-146a & Scleroderma & Smad4 & 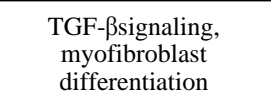 & {$[37,78]$} \\
\hline miRNA-382 & Keloids & $\begin{array}{l}\text { MAPK, TGF- } \beta \text {, and } \\
\text { the synthesis of } \\
\text { collagen }\end{array}$ & ECM synthesis & [36] \\
\hline miRNA-503 & Scleroderma & Smad7 & TGF- $\beta$ signaling & [78] \\
\hline miRNA-4269 & Keloids & $\begin{array}{l}\text { MAPK, TGF- } \beta \text {, and } \\
\text { the synthesis of } \\
\text { collagen }\end{array}$ & ECM synthesis & [36] \\
\hline
\end{tabular}


Table 2

MiRNAs downregulated in skin fibrosis

\begin{tabular}{|c|c|c|c|c|}
\hline MicroRNA & $\begin{array}{l}\text { Associated } \\
\text { fibrotic skin } \\
\text { diseases }\end{array}$ & Notable targets & $\begin{array}{l}\text { Key skin fibrotic } \\
\text { processes }\end{array}$ & References \\
\hline Let-7a & Scleroderma & Collagen type I & ECM synthesis & [38] \\
\hline miRNA-7 & $\begin{array}{l}\text { Localized } \\
\text { scleroderma, } \\
\text { keloids }\end{array}$ & Collagen type I & ECM synthesis & [15] \\
\hline $\begin{array}{l}\text { MiRNA-17- } \\
5 \mathrm{p}\end{array}$ & $\begin{array}{l}\text { Hypertrophic } \\
\text { scars }\end{array}$ & $\mathrm{TGF}_{2} \mathrm{R}$ & TGF- $\beta$ s signaling & [51] \\
\hline MiRNA-18 & $\begin{array}{l}\text { Hypertrophic } \\
\text { scars }\end{array}$ & Smad4 & TGF- $\beta$ s signaling & [51] \\
\hline MiRNA-20 & $\begin{array}{l}\text { Hypertrophic } \\
\text { scars }\end{array}$ & $\mathrm{TGF}_{2} \mathrm{R}$ & TGF- $\beta$ s signaling & [51] \\
\hline miRNA-26a & $\begin{array}{l}\text { Scleroderma, } \\
\text { keloids }\end{array}$ & Collagen type I & ECM synthesis & [15] \\
\hline miRNA-29 & Scleroderma & $\begin{array}{l}\text { Collagen types I and III, } \\
\text { elastin, fibrillin, Wnt/beta } \\
\text { catenin, NF- } \kappa, \text { BMAPK }\end{array}$ & ECM synthesis & $\begin{array}{c}{[11,19,41,49,} \\
78]\end{array}$ \\
\hline $\begin{array}{l}\text { miRNA-129- } \\
5 \mathrm{p}\end{array}$ & $\begin{array}{l}\text { Scleroderma, } \\
\text { keloids }\end{array}$ & Collagen type I & ECM synthesis & {$[15]$} \\
\hline miRNA-133a & Scleroderma & Collagen types V and VI & ECM synthesis & [34] \\
\hline $\begin{array}{l}\text { miRNA- } \\
133 \mathrm{~b}\end{array}$ & $\begin{array}{l}\text { Scleroderma, } \\
\text { keloids }\end{array}$ & Collagen type I & ECM synthesis & [15] \\
\hline \multirow{2}{*}{$\begin{array}{l}\text { miRNA-140- } \\
5 \mathrm{p}\end{array}$} & \multirow{2}{*}{ Scleroderma } & $\mathrm{TFG} \beta_{2} \mathrm{R}$ & TGF- $\beta$ s signaling & [34] \\
\hline & & Collagen type I & ECM synthesis & [34] \\
\hline miRNA-145 & Scleroderma & Smad3 & TGF- $\beta$ s signaling & [78] \\
\hline miRNA-150 & Scleroderma & $\begin{array}{l}\text { Integrin } \beta 3 \text { (indirectly } \\
\text { collagen type I }\end{array}$ & ECM synthesis & [21] \\
\hline miRNA-196a & $\begin{array}{l}\text { Scleroderma, } \\
\text { keloids }\end{array}$ & Collagen types I and III & ECM synthesis & {$[20,29]$} \\
\hline miRNA-200 & Keloids & Zeb1, Zeb2, TGF- $\beta 2$ & $\begin{array}{l}\text { Epithelial-to- } \\
\text { mesenchymal } \\
\text { transition }\end{array}$ & {$[8,44]$} \\
\hline miRNA-203 & Keloids & $\begin{array}{l}\text { MAPK, TGF- } \beta \text {, and the } \\
\text { synthesis of collagen }\end{array}$ & ECM synthesis & [36] \\
\hline miRNA-205 & Keloids & $\begin{array}{l}\text { MAPK, TGF- } \beta \text {, and the } \\
\text { synthesis of collagen }\end{array}$ & ECM synthesis & [36] \\
\hline \multirow[t]{2}{*}{ miRNA-206 } & Scleroderma & $\mathrm{TFG} \beta_{1}, \mathrm{TFG} \beta_{2}$ & TGF- $\beta$ s signaling & [34] \\
\hline & & Collagen types VI and XIX & ECM synthesis & [34] \\
\hline
\end{tabular}

